Preprint, for presentation at the 217th ACS National Meeting to be held in Anaheim, CA on

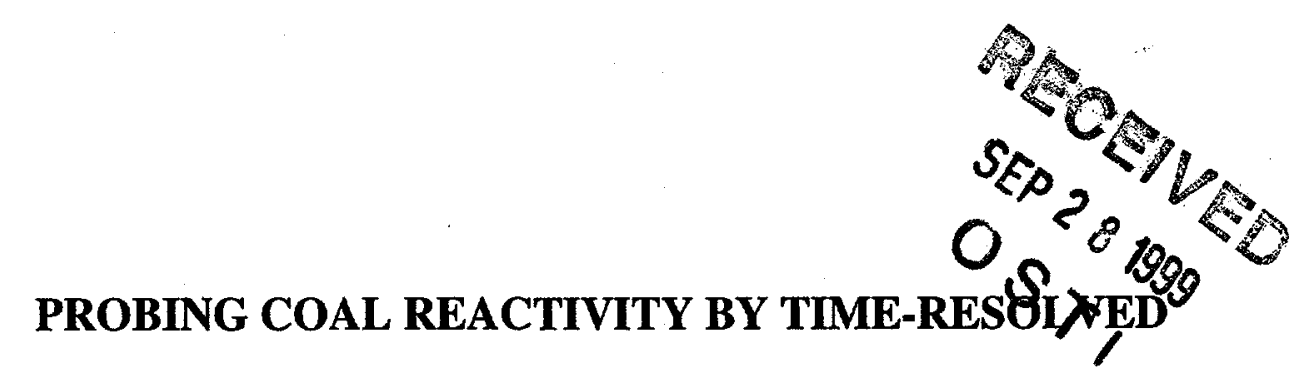

SMALL ANGLE X-RAY SCATTERING*

$\underline{\text { R. E. Winans, S. Seifert, and P. Thiyagarajan }}{ }^{\dagger}$

Chemistry Division and ${ }^{\dagger}$ Intense Pulsed Neutron Source Division

Argonne National Laboratory

Argonne, IL 60439

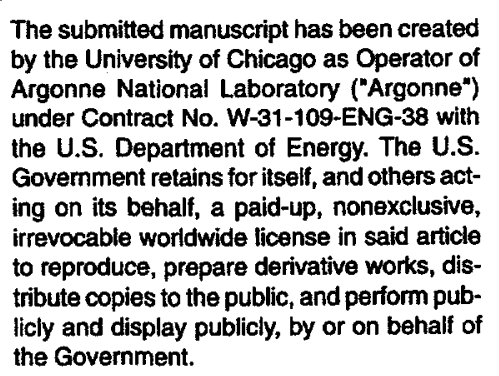

*This work was performed under the auspices of the Office of Basic Energy Sciences, Division of Chemical Sciences and Division of Materials Sciences, U.S. Department of Energy, under contract number W-31-109-ENG-38. 


\section{DISCLAIMER}

This report was prepared as an account of work sponsored by an agency of the United States Government. Neither the United States Government nor any agency thereof, nor any of their employees, make any warranty, express or implied, or assumes any legal liability or responsibility for the accuracy, completeness, or usefulness of any information, apparatus, product, or process disclosed, or represents that its use would not infringe privately owned rights. Reference herein to any specific commercial product, process, or service by trade name, trademark, manufacturer, or otherwise does not necessarily constitute or imply its endorsement, recommendation, or favoring by the United States Government or any agency thereof. The views and opinions of authors expressed herein do not necessarily state or reflect those of the United States Government or any agency thereof. 


\section{DISCLAIMER}

Portions of this document may be illegible in electronic image products. Images are produced from the best available original document. 


\title{
PROBING COAL REACTIVITY BY TIME-RESOLVED SMALL ANGLE X-RAY SCATTERING
}

\author{
R. E. Winans, S. Seifert, and P. Thiyagarajan ${ }^{\dagger}$ \\ Chemistry Division and 'Intense Pulsed Neutron Source Division \\ Argonne National Laboratory \\ Argonne, IL 60439
}

Keywords: Argonne coal swelling, time-resolved small angle neutron scattering

\begin{abstract}
The objective of this study is to observe changes in coal structure in situ with small angle X-ray scattering (SAXS) during solvent swelling and during pyrolysis. We have built a SAXS instrument at the Basic Energy Sciences Synchrotron Research Center at the Advanced Photon Source that allows us to obtain scattering patterns in the millisecond time domain. The eight Argonne Premium Coal samples were used in this study. The information that can be derived from these experiments, such as changes in fractal dimensionality and in size and type of porosity, was found to be very rankdependent. In the swelling experiments, it was noted that for certain coals, structural changes occurred in just a few minutes.
\end{abstract}

\section{INTRODUCTION}

Coal solvent interactions have been studied extensively over the last 25 years. Most coals swell significantly in solvents such as pyridine and this effect has been exploited to study the macromolecular structure of coals (1-8). Typically, the volumetric swell ratio $\left(Q_{v}\right)$ is measured and is defined as the ratio of the swollen volume over the dry volume. Recently, the swelling of individual particles was determined using microscopy combined with video and image analysis (9). Otake and Suuberg studied the temperature dependence of the rate of swelling on some of the Argonne Premium Coal Samples (10). Also, they looked at a larger set of low rank coals (11). They found large differences in the rate of coal swelling with the Illinois No. 6 (APCS 3) being the fastest and the lignite (APCS 8) the slowest. The Upper Freeport (APCS 1) has been studied extensively in part due to its unusually large solubility in the NMP/CS 2 mixed solvent system (12).

Small angle neutron scattering (SANS) has been used to study swollen coals and extracts. For the Pittsburgh coal (APCS 4), it was shown that a rod-like pore structure developed upon swelling in pyridine (13). It has also been shown that pyridine solubles are not truly soluble (14). Finally, the Upper Freeport coal was studied extensively with SANS on both soluble and insoluble fractions for $\mathrm{NMP} / \mathrm{CS}_{2}$ and pyridine (15).

The present study exploits the brilliance of the undulator X-ray source at the Advanced Photon Source to probe, in real time, the structure changes in coal swelling using SAXS. The information derived from the SAXS experiment throws new light on the early stages of structure changes in coal swelling.

\section{EXPERIMENTAL}

The eight Argonne Premium Coal Samples were used without modification in this study (16). The SAXS instrument was constructed at ANL and used on the Basic Energy Sciences Synchrotron Radiation Center CAT undulator beamline $\mathrm{ID}-12$ at the Advanced Photon Source (http://www.bessrc.aps.anl/).

Quartz capillaries $(1 \mathrm{~mm}$ ) were used to sample $5 \mathrm{mg}$ of -100 mesh coal. Scattering patterns were obtained on the dry coal, then $10 \mu \mathrm{l}$ of solvent was added with a syringe such that all the sample was wetted. SAXS data were obtained every minute for one hour with approximately a one minute delay after adding the solvent. Monochromatic X-rays $(8.5-23.0 \mathrm{keV})$ are scattered off the sample and collected on a $19 \times 19 \mathrm{~cm}^{2}$ position sensitive two-dimensional gas detector. The scattered intensity has been corrected for absorption, the empty capillary scattering, and instrument background. The differential scattering cross section has been expressed as a function of the scattering vector $Q$, which is defined as:

$$
Q=\frac{4 \pi}{\lambda} \sin \theta
$$


where $\lambda$ is the wavelength of the $\mathrm{X}$-rays and $\theta$ is the scattering half angle. The value of $\mathrm{Q}$ is proportional to the inverse of the length scale $\left(\AA^{-1}\right)$. The instrument was operated with two different sample-to-detector distances, $68.5 \mathrm{~cm}$ to obtain data at $0.04<Q<0.7 \AA^{-1}$ and $3740 \mathrm{~cm}$ to measure at $0.006<\mathrm{Q}<0.1 \AA^{-1}$.

\section{Small Angle X-ray Scattering}

A typical two-dimensional plot of the time-resolved data for the swelling of the subbituminous coal (APCS 2) in pyridine is shown in Figure 1. These curves can be analyzed to determine size of features, topology, and changes in total scattering. At small $Q$ in the Guinier region, the radius of gyration $\left(R_{g}\right)$, which is related to the size of the scattering features, can be determined. For example, $R_{g}$ for spheres can be determined from the slope of $I(Q)$ vs $Q^{2}$ in a $Q$ region where $R_{g} Q \leq 1.0$. Power law slope (fractal dimension) from the data, such as is shown in Figure 1, are used to describe the topology of the system. Finally, the invariant $\mathrm{Q}_{0}$ is calculated and is proportional to the fluctuation of the electron density in the system. Changes in the invariant are useful in monitoring topological changes in the sample.

$$
\mathrm{Q}_{0}=\int_{0}^{\infty} \mathrm{I}(\mathrm{Q}) \mathrm{Q}^{2} \mathrm{dQ}
$$

For example, the invariant goes to zero for a homogeneous system such as a solution of coal molecules that are truly soluble and not aggregated.

\section{RESULTS AND DISCUSSION}

This discussion will focus on four of the Argonne coals: lignite, Illinois \#6, subbituminous, and Upper Freeport. The slowest swelling coal, lignite (APCS 8), at $25^{\circ} \mathrm{C}$ took $230 \mathrm{~min}$. to reach $50 \%$ of final swelling $\left(\mathrm{t}_{50}\right)(10)$, while the Illinois $\# 6$ at $24{ }^{\circ} \mathrm{C}$ had a $\mathrm{t}_{50}$ of $1.7 \mathrm{~min}$. The subbituminous coal was chosen since its swelling rate is of an intermediate value, $t_{50}=12.8 \mathrm{~min}$. at $24{ }^{\circ} \mathrm{C}$ and its results correlate well with those described in the literature (10). Finally, the Upper Freeport was examined with two solvent systems, pyridine and NMP/CS 2 with very different results between the two solvents.

A set of sixty scattering curves are shown in Figure 1 for the subbituminous coal in pyridine. Initially, there are only small changes, then between 10 and $25 \mathrm{~min}$., the slope and invariant decreased quite rapidly. The change in fractal dimensions is shown in Figure 2 for all four of the coals. It appears that the decrease in the fractal dimension is stopped when the subbituminous coal is fully swollen. Between 10 and $35 \mathrm{~min}$. this data fits an exponential decay with a constant of 0.16 $\min ^{-1}$. For short length scales $<30 \AA$, there appears to be an increase in the scattering when the swelling has finished. After the macromolecular structure has expanded, changes at the molecular level can be discerned.

The swelling of Illinois \#6 was very rapid, therefore, the changes seen with time in the SAXS data must be due to a molecular aggregation that started after $20 \mathrm{~min}$. However, this new configuration was not stable and slowly rearranged between 30 and $60 \mathrm{~min}$. This was seen much better in the changes of the power law slope as shown in Figure 2. This unusual phenomenon was reproducible and appeared limited to the Illinois coal.

At room temperature, no changes in either the invariant or power law slope were observed for the lignite coal. However, the experiment was repeated at $50{ }^{\circ} \mathrm{C}$, where $\mathrm{T}_{50} \approx 25 \mathrm{~min}$. At low $\mathrm{Q}$, the power law slope decreased, but this change was much smaller than those observed for the other coals. These higher temperature experiments need to be run at high $Q$ to see if changes on a smaller length scale is occurring. In addition, acid treated lignite will be studied. There is considerable organic acid-mineral interactions in lignite.

The Upper Freeport mv bituminous coal does not swell as well as other coals, $Q_{v}=1.3(12)$, while all the other lower rank coals sweil with $\mathrm{Q}_{\mathrm{v}} \geq 2.0$. In NMP/CS , the ratio was rot measured on the raw coal since it is very soluble (12). In pyridine, a rapid increase in the invariant occurred and then it remained constant after approximately $10 \mathrm{~min}$. (see Figure 3 ). While the invariant in NMP/CS starts at about the same value and does increase, the magnitude of the increase is much less, and after $10 \mathrm{~min}$., it starts to decrease. Pyridine must decrease the surface area in the coal possibly by dissolution followed by re-aggregation. We know from SANS that pyridine solutions are actually aggregates (14). It is interesting that while NMP/CS ${ }_{2}$ is a good extraction solvent for the Upper Freeport, it does not appear to greatly change the 3D structure on the length scales studied here. 


\section{CONCLUSIONS}

Structure changes in initial solvent swelling are observed in the time-resolved SAXS data from the coals. With high rank coals in pyridine, there is a rapid breakup of the solid structure, followed by a re-aggregation that produces constant scattering. With $\mathrm{NMP} / \mathrm{CS}_{2}$, the effect is much smaller and the scattering decreases with time. For the subbituminous coal, the scattering increases immediately, probably forming a new pore structure with rod-like features.

\section{ACKNOWLEDGMENTS}

This work was performed under the auspices of the Office of Basic Energy Sciences, Division of Chemical Sciences and Division of Materials Sciences, U.S. Department of Energy, under contract number W-31-109-ENG-38. The support of the BESSRC staff is appreciated, especially Jennifer Linton and Mark Beno.

\section{REFERENCES}

1. Larsen, J. W.; Shawver, S. Energy Fuels 1990, 4, 74.

2. Cody, G. D.; Eser, S.; Hatcher, P.; Davis, A.; Sobkowiak, M.; Shenoy, S.; Painter, P.C. Energy Fuels 1992, 6, 716.

3. Hall, P. J.; Larsen, J. W. Energy Fuels 1993, 7, 47.

4. Suuberg, E. M.; Otake, Y.; Yun, Y.; Deevi, S. C. Energy Fuels 1993, 7, 384.

5. Yang, X.; Larsen, J. W.; Silbernagel, B. G. Energy Fuels 1993, 7, 439.

6. Ndaji, F. E.; Thomas, K. M. Fuel 1993, 72, 1525.

7. Aida, T.; Nawa, Y.; Shiotani, Y.; Yoshihara, M.; Yonezawa, T. Conf. Proc. - Int. Conf. Coal Sci., $7^{\text {th }} 1993,2,445$.

8. Larsen, J. W.; Gurevich, I.; Glass, A. S.; Stevenson, D. S. Energy Fuels 1996, 10, 1269.

9. Gao, H.; Artok, L.; Kidena, K.; Murata, S.; Miura, M.; Nomura, M. Energy Fuels 1998, 12, 881.

10. Otake, Y.; Suuberg, E. M. Energy Fuels 1997, 11, 1155.

11. Otake, Y.; Suuberg, E. M. Fuel 1998, 77, 901.

12. Takanohashi, T.; lino, M.; Nishioka, M. Energy Fuels 1995, 9, 788.

13. Winans, R. E.; Thiyagarajan, P. Energy Fuels 1988, 2, 356.

14. Cody, G. D.; Thiyagarajan, P.; Botto, R. E.; Hunt, J. E., Winans, R. E. Energy Fuels 1994, $8,1370$.

15. Cody, G. D.; Obeng, M.; Thiyagarajan, P. Energy Fuels 1997, 11, 495.

16. Vorres, K. S. Energy Fuels 1990, 4, 420.

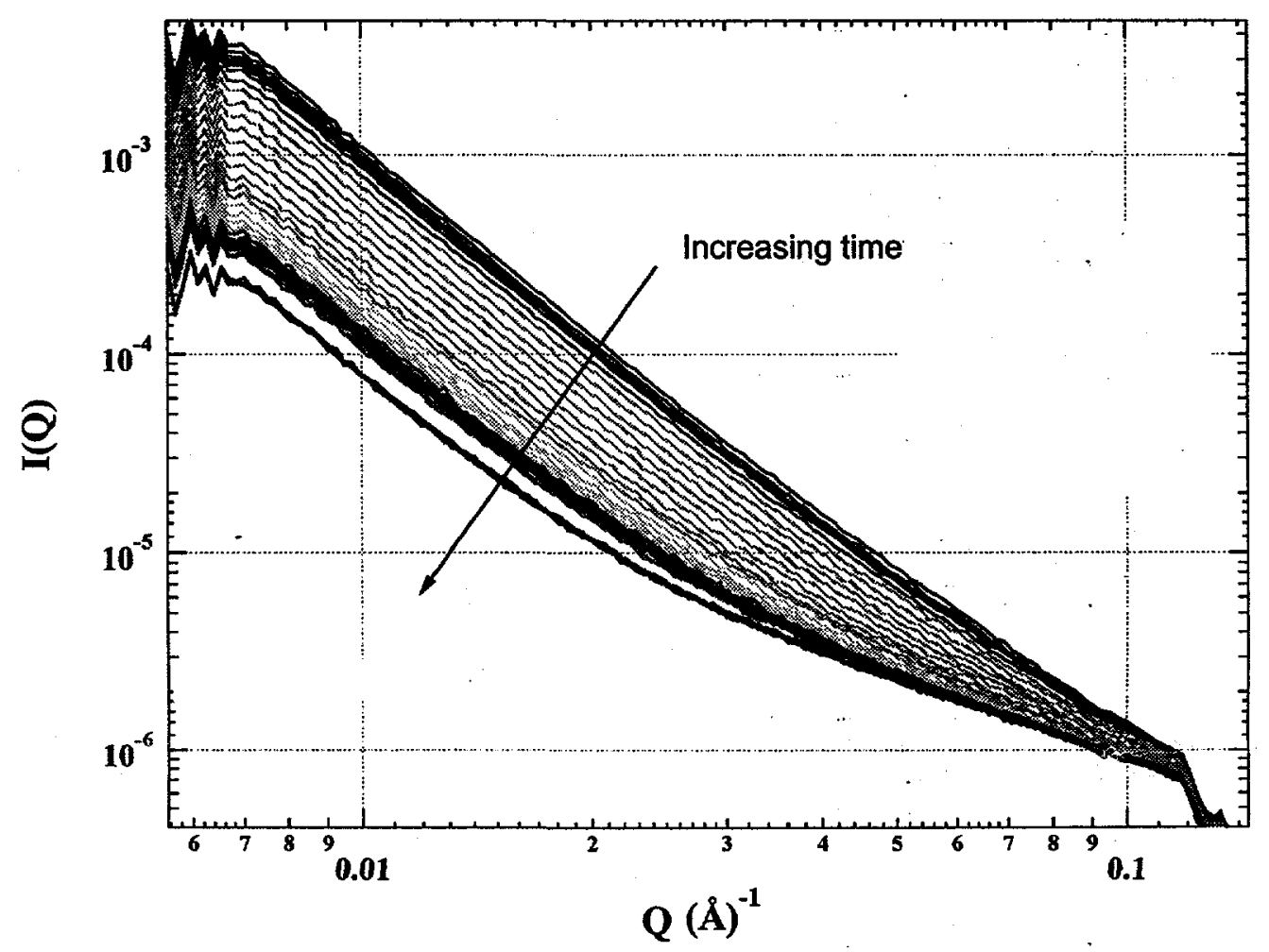

Figure 1. SAXS of the subbituminous coal (APCS 2) in pyridine from 1 to 60 minutes. 


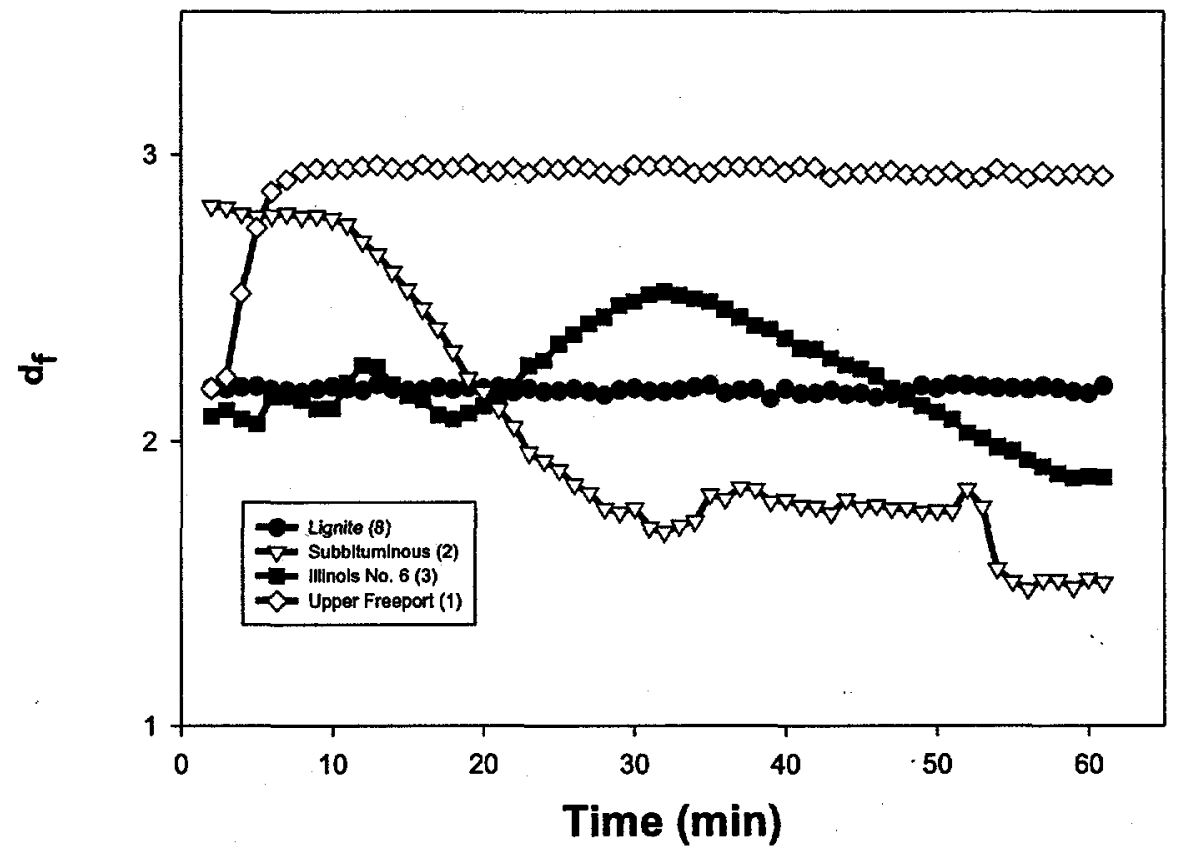

Figure 2. Power law slopes (fractal dimensions) for coal swelling in pyridine at low $\mathrm{Q}$, as a function of solvent contact time.

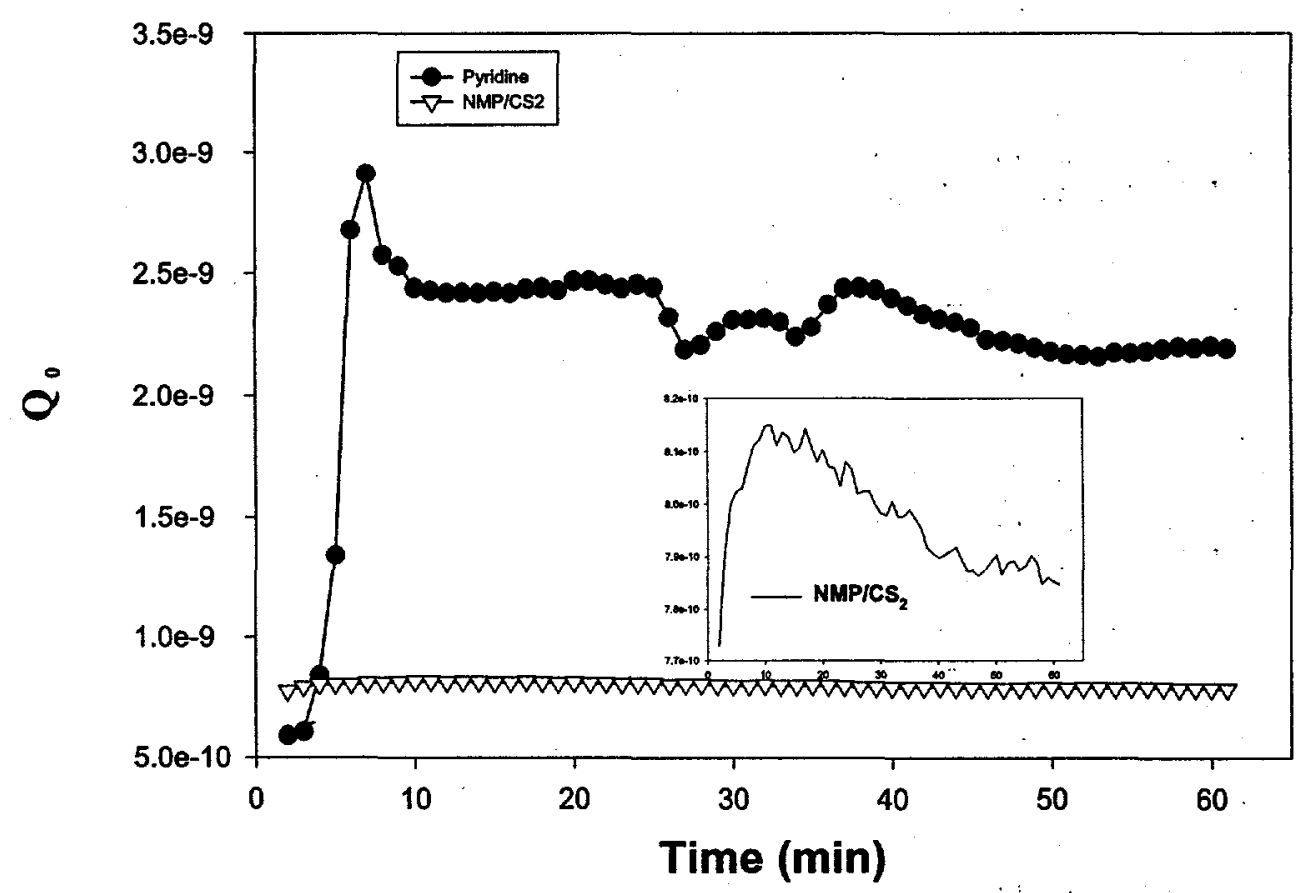

Figure 3. Invariant change with swelling in pyridine and $\mathrm{NMP} / \mathrm{CS}_{2}$ for the Upper Freeport coal. The inset is an exploded view in $\mathrm{Q}_{0}$ for the NMP/CS data. 